\title{
Consumo de carnes en zonas cálidas del Nuevo Reino de Granada: cualidades cambiantes, siglos XVI y XVII
}

\author{
Gregorio Saldarriaga \\ Universidad de Antioquia, Colombia \\ gregario@yahoo.com
}

\begin{abstract}
Resumen $^{1}$
El artículo trata sobre la producción y consumo de carne de cerdo y de algunos animales americanos en zonas cálidas de alto tráfico comercial del Nuevo Reino de Granada, durante los siglos XVI y XVII. El objetivo es mostrar que el aumento en el consumo de carnes, con respecto a la dieta europea mediterránea, producía cambios en las concepciones de la vida que tenía la sociedad colonial. Asimismo, se muestra que en un ambiente de dominación hispánica, los usos indígenas tradicionales de consumo de ciertos animales americanos se transformaban drásticamente, pasando a ser utilizados y aprovechados para el abastecimiento de las ciudades, villas y puertos. La información sobre la cual se basa esta investigación proviene del fondo Visitas del Archivo General de la Nación (Bogotá) y de fuentes impresas, entre las cuales cabe destacar algunas que no han sido frecuentes en los estudios sobre el Nuevo Reino de Granada.
\end{abstract}

Palabras clave: SIGLO XVI, SIGLO XVII, CARNE, ALIMENTACIÓN, CERDOS, MANATÍ.

\begin{abstract}
The article deals on the production and consumption of pork and meats from some American animals in the high-traffic commercial temperate zones of the New Kingdom of Granada, during the $16^{\text {th }}$ and $17^{\text {th }}$ centuries. The objective is to show that the increase in the consumption of meats, as compared to the Mediterranean European diet, produced changes in the colonial society's concepts on life. Additionally, it shows that amid an atmosphere of Hispanic domination, certain indigenous traditional uses of American animal meats were transformed drastically, beginning to be used for supplying cities, villas and ports. The investigation is based on information from the fondo de Visitas del Archivo General de la Nación (Bogotá) and from printed sources, some of which have been of notably infrequent use in the studies on the New Kingdom of Granada.
\end{abstract}

Key words: 16th CENTURY, 17th CENTURY, MEAT FOODS, PORK, MANATÍ.

\footnotetext{
${ }^{1}$ Esta investigación fue desarrollada gracias a la ayuda económica asignada por el Icanh, dentro del programa de financiación de trabajos de historia colonial. Agradezco los comentarios y sugerencias hechas a este trabajo por Pilar Gonzalbo, Massimo Montanari, Luis Miguel Córdoba y Adriana Fontán.
} 


\section{Crecimiento en un suelo nuevo}

En el suelo indiano, los ganados del Viejo Mundo encontraron un espacio propicio para su expansión y los rebaños alcanzaron proporciones que hasta ese momento eran desconocidas. Como avanzada de la sociedad que se estaba construyendo en el Nuevo Mundo, vacas y toros, cerdos, cabras y carneros parecieron apropiarse del mandato bíblico, pues fueron fecundos, se multiplicaron, hinchieron la tierra y la sometieron ${ }^{1}$. Al poco tiempo de llegar, se acomodaron tan bien y ocuparon tantos espacios que ya era imposible pensar que las Indias no fueran el sitio más adecuado para la cría de ganado ${ }^{2}$. Bien fuera como animales domésticos reunidos bajo el mando de un pastor o como bestias cimarronas, parecían no existir sitios en los cuales no se hallaran presentes, por lo menos en una de sus variedades. El Nuevo Reino de Granada y Popayán no fueron ajenos a esta situación, pues a lo largo y ancho de sus provincias se esparcieron los especímenes: la cabra se restringió a unas cuantas zonas; el carnero sólo se criaba en las zonas frías con suficiente población consumidora; por su parte, el cerdo fue casi omnipresente, y allí donde no se levantara, era fácil conseguirlo por medio del comercio; la vaca tuvo una suerte similar. Parte de este éxito radicó en la ausencia de ganados domésticos nativos en América que compitieran con ellos, en la abundancia de tierras de pastoreo, en el uso de un nuevo pienso, del que había en cantidad y en alto rendimiento alimentario, como el maíz ${ }^{3}$, aunado a la voluntad de los españoles de levantar estas manadas para que pasaran a hacer parte básica de su dieta. Al margen de estas explicaciones, en los montes se criaron ganados cimarrones que llegaban a las mesas por medio de la cacería ${ }^{4}$. Igualmente allí, los animales indígenas siguieron su ciclo normal sin llegar a ser domesticados, pero sí formaron parte de la dieta de algunos sitios, villas o ciudades; entre estos estaba el saíno, el

\footnotetext{
${ }^{1}$ Gén. 1: 28.

${ }^{2}$ Alfred Crosby, Imperialismo ecológico: la expansión biológica de Europa, 900-1900, trad. Iniesta Montserrat (Barcelona: Crítica, 1999); Elizabeth Reitz, "Dieta y alimentación hispano-americana en el Caribe y la Florida en el siglo XVI", Revista de Indias (Madrid), 51, núm. 191 (1991): 11-24.

${ }^{3}$ Arturo Warman, Historia de un bastardo: maíz y capitalismo (México: Fondo de Cultura Económica, 1988).

${ }^{4}$ La práctica de cazar animales cimarrones se encontraba extendida en el Nuevo Reino de Granada y las Indias en general, pero fue en las Antillas, en donde se dio con mayor intensidad, por parte tanto de especialistas (bucaneros o matadores) que hacían de ese oficio su forma de vida, como de particulares que solo buscaban la carne del día. Véase Alexandre Olivier Exquemeling, Historias de piratas. Diario de un cirujano de a bordo (Buenos Aires: Biblioteca Fundamental del Hombre Moderno, 1972); Jean Baptiste Labat, Viajes a las islas de la América, trad. Francisco de Oraá (La Habana: Casa de las Américas, 1979); Diego de Ocaña, A través de la América del Sur, ed. Arturo Álvarez (Madrid: Historia 16, 1987).
} 
tapir y el armadillo, así como ciertos animales que iban del agua a la tierra con cierta facilidad: iguana, manatí y caimán.

Esta abundancia de carnes disponibles hizo que cambiara considerablemente la dieta de los españoles llegados a las Indias, quienes, como toda la Europa mediterránea, tenían un alto consumo de pan y carbohidratos, y uno bajo de carne ${ }^{5}$. Parecía que en los reinos de ultramar las bestias estaban dispuestas al sacrificio todo el tiempo y que incluso el más pobre podía comer toda la carne que quisiera ${ }^{6}$. La máxima expresión de esta abundancia eran los relatos sobre los cazadores que mataban vacas para consumir solo sus lenguas o ubres, mientras que el resto quedaba a disposición de los carroñeros ${ }^{7}$. Si bien estos relatos eran ciertos, no por ello eran generalizados, y en muchos sitios de las Indias, del Nuevo Reino y de Popayán, los ganados no eran abundantes y solo llegaban allí tras penosas travesías que los dejaban flacos y duros, o como pedazos de tasajo, conservados en sal. Sin embargo, en casi todo el Nuevo Reino de Granada y Popayán hubo un abastecimiento continuo que permitió que el hambre y la carencia de proteína animal fueran cosas que habían quedado al otro lado del Atlántico ${ }^{8}$.

Este aumento en el consumo de carne produjo cambios en la dieta, en la concepción de lo que significaba la abundancia, lo saludable y la calidad de los productos consumidos; asimismo, con él se crearon identidades alimentarias en torno a los productos y a la manera en que se consumían. En este artículo tratar trataré de mostrar estos cambios ejemplificados en el consumo de los cerdos y los anfibios americanos (caimán, iguana, manatí y tortuga), así como de sus productos derivados, porque en ellos estos procesos fueron particularmente visibles.

\section{El cerdo}

\footnotetext{
${ }^{5}$ Máximo Montanari, Del hambre a la abundancia. Historia y cultura de la alimentación en Europa (Barcelona: Crítica, 1993), 113.

${ }^{6}$ Thomas Gage, Nueva relación que contiene los viajes de Tomás Gage a la Nueva España, sus diversas aventuras y su vuelta por la provincia de Nicaragua hasta la Habana, con la descripción de la ciudad de México, prólogo de Artemio de Valle-Arizpe (México: Ediciones Xochitil, 1947), parte 3, cap. 1: 288 y cap. 4: 334; Jesús Contreras, "Los aspectos culturales en el consumo de carne", en Somos lo que comemos, coord. Mabel Gracia Arnaiz (Barcelona: Ariel, 2002), 230; Enrique Otte, comp., Cartas privadas de emigrantes a Indias, 1540-1666, prólogo de Ramón Carande y Thovar (México: Fondo de Cultura Económica, 1993), 325.

${ }^{7}$ Exquemeling, Historias de piratas, 12.

${ }^{8}$ En las cartas de inmigrantes a Indias esta asociación es muy clara. Siempre hacen referencia a la abundancia de comida, aunque no necesariamente de riqueza. Véase Otte, Cartas privadas, 296, 325- 326.
} 
Como parte de sus instrumentos de conquista y poblamiento, los españoles cargaron con sus ganados y algunas semillas que les ayudaran a mantener la dieta, tal como pensaban que debería ser. Cuando los resultados de la empresa no eran satisfactorios y los llevaba por territorios despoblados y sin mantenimientos, estos ganados y semillas era lo primero que se consumía; y si la situación persistía, seguían su camino los perros y los caballos. Pero si la fortuna les sonreía, las piaras de cerdos servían como avanzada que permitía asentarse en una región con ciertas seguridades alimentarias y mantener la dieta bajo unos parámetros de expectativa apropiados ${ }^{9}$. En ocasiones, esas expectativas hacían que hasta mediados del siglo XVI el precio de los porcinos alcanzara altísimos precios, que solo era posible pagar con las riquezas que la conquista y el rancheo habían dejado a unos cuantos ${ }^{10}$.

De esta manera se aseguraban provisiones y se establecían los valores alimentarios que el grupo conquistador poseía y esperaba que se mantuvieran intactos; si bien en los reinos de España las carnes preferidas eran las de cabra y carnero ${ }^{11}$, unas y otros presentaban problemas de aclimatación, por lo cual su asentamiento era muy difícil. En cambio, el cerdo era de fácil adaptación a todos los terrenos e imponía unas marcas de distinción especiales: al ser un animal impuro para judíos y musulmanes, el consumidor se reivindicaba tácitamente como cristiano viejo, libre de mácula o de sospecha $^{12}$, lo cual no era poco en una sociedad que había comenzado el proceso de segregación con unos y otros casi que paralelamente al descubrimiento de América, y más cuando se sospechaba que moriscos y judíos habían tomado rumbo a las Indias para tratar de esconder su condición en esta nueva tierra de frontera, y alejarse de aquellos que pudieran descubrirlos como tales. Así, cada comida en la que hubiera puerco, como plato principal o preparada

\footnotetext{
${ }^{9}$ La expedición de Belalcázar llevó a los términos de Santafé 300 marranas preñadas a mediados de abril de 1539. Melchor Pérez de Arteaga, "Relación del Nuevo Reino. Carta y relación [...]", en No hay caciques ni señores: relaciones y visitas a naturales de América, siglo XVI, Hermes Tovar (Barcelona: Sendai, 1988), 114.

10 "'[...] se vendió una puerca en mil seiscientos pesos, con otros cochinos; y se vendían cochinos pequeños a quinientos pesos [...]; de los vientres de las puercas compraban antes que naciesen, los lechones a cien pesos y más.” Pedro de Cieza de León, La crónica del Perú. Obras completas ([¿1553?]; Madrid: CSIC; Instituto Gonzalo Fernández de Oviedo, 1984), t. 1, parte 1, cap. 26: 38; Colección de Documentos Inéditos Relativos al Adelantado Capitán Don Sebastián de Benalcázar, 1535-1565 -en adelante CDISB-, trans. Jorge A. Garcés (Quito: Publicaciones del Archivo Municipal, 1936), 284.

11 Xavier Domingo, "La cocina precolombina en España", en Conquista y comida. Consecuencias del encuentro de dos mundos, coord. Janet Long (México: Universidad Nacional Autónoma de México, 1996), 25.

${ }^{12}$ Alberto Capatti, y Massimo Montanari. Italian Cuisine. A cultural History (Nueva York: Columbia University Press, 2003), 4; Jean-Louis Flandrin, "Le goût et la nécessité: sur 1'usage des graisses dans les cuisines d'Europe occidentale (XIV $-\mathrm{XVIII}{ }^{\mathrm{e}}$ siècle)", Annales ESC (París), 38, núm. 2 (marzo-abril 1983): 388.
} 
con su manteca, era una pequeña ordalía en la cual cada uno pretendía demostrar lo que era y por lo que debía ser tenido ${ }^{13}$.

A esto se le debe sumar el gusto que los españoles sentían por las preparaciones hechas con este animal y el saber culinario que a lo largo de siglos se había consolidado en platos, jamones y embutidos. Así, en el Nuevo Reino de Granada y Popayán, se buscó recrear la actividad de producción porcina tal y como la conocían en España, para servirse de ella de la misma manera como lo hacían en la península. Como es normal en los procesos de transculturación, los resultados no fueron iguales a los esperados, pues la producción excedió con mucho a la que se daba en España, y si bien los productos elaborados siguieron los mismos patrones, hubo cambios que trastocaron su sabor por la introducción de nuevos ingredientes (ajíes y achiote). El cambio más importante fue una percepción generalizada: el cerdo en algunas zonas del Nuevo Reino y de las Antillas tenía mejor gusto y otra calidad que en España

Como se mencionó anteriormente, gran parte del éxito en la producción ganadera radicó en las posibilidades de contar con tierras de pastoreo en las cuales los cerdos podían explayarse a sus anchas, sin tener contrincantes que les disputaran el terreno; más importante aún fue el alimento que se les daba y la mano de obra que los cuidaba.

\section{Crianza de cerdos}

En la Conquista, para los indios el cerdo fue "verdadera encarnación animal del impacto desencadenado por la irrupción de los cristianos"14, pues arrasó sus cultivos sin que hubiera previsión posible contra este ataque inesperado. Posteriormente, los ganados porcinos siguieron comiendo de las rozas de maíz y de yuca de los indios ${ }^{15}$; en muchos casos, era claro que los dueños de las piaras buscaban ubicarlas cerca de los pueblos para que tuvieran alimentos gratuitos, sin tener que preocuparse por responder a las quejas de los indios ${ }^{16}$. Más allá de esto,

\footnotetext{
${ }^{13} \mathrm{~A}$ los judaizantes, por falta de más alimentos, les tocó comer cerdo o viandas preparadas con su grasa.

${ }^{14}$ Carmen Bernand y Serge Gruzinski, Historia del Nuevo Mundo, t. 1 (México: Fondo de Cultura Económica, 1996), 226.

${ }^{15}$ Hay dos tipos de yuca: la dulce y la brava. La primera puede ser consumida cruda o con una leve cocción, mientras que la segunda debe ser tratada para quitarle su veneno, que es mortal. Los cerdos, según Fernández de Oviedo, distinguían entre una y otra y solo comían de la inocua. Gonzalo Fernández de Oviedo, Sumario de la natural historia de las Indias, ed. Manuel Ballestero Gaibrois ([¿1525?]; Madrid: Dastin, 2002), cap. 5: 71.

16 "Indios de Bosa. Investigación sobre los malos tratos que les daban con motivo de la extracción de oro en el corregimiento de Ontibon de la Real Corona. Contra el licenciado Miguel Días", en Relaciones y visitas a los Andes. Siglo XVI, ed. Hermes Tovar. (Bogotá:
} 
que siempre fue un problema irresoluto, muchos indígenas aprendieron a criar cerdos, bien fuera para su provecho personal o para trabajar como porqueros para sus encomenderos (lo cual era más frecuente), así como también lo hicieron muchos esclavos y libertos. Sin unos y otros no era posible comprender la multiplicación de los puercos ${ }^{17}$. Ellos eran los encargados de cuidarlos, transportarlos y alimentarlos, lo cual sin duda era uno de los puntos principales, pues, al estar encargados también del proceso de producción agrícola o muy cercanos a él, tenían más posibilidades de alimentar con mayor presteza los chanchos con maíz, yuca y, en menor medida, cebada (solo en las regiones frías que la cultivaban) ${ }^{18}$. De esta manera se fueron configurando sociedades porqueras basadas en el trabajo indígena y negro. Este último, aunque más reducido a mediados del siglo XVI, aumentó con el paso del tiempo hasta consolidarse alrededor de las primeras décadas del XVII.

Estas sociedades porqueras se establecieron en casi todo el Nuevo Reino de Granada y Popayán, ya que el cerdo se da bien en prácticamente todos los climas. Hubo unas de menor envergadura que buscaban el sostenimiento básico de su población y otras de gran calado que trataban de alimentar zonas de activo movimiento comercial. Aunque de estas últimas faltarán algunas, haré mención de las más importantes: la ciudad de Cartagena tuvo a su disposición casi toda la gobernación del mismo nombre para que la proveyera del ganado porcino que necesitaba para sus habitantes y para el abasto de las naves que llegaban; la producción se establecía en tres ejes: el primero estaba a lo largo de la costa, especialmente hacia el occidente, en donde la villa de Tolú ocupaba un lugar importante; el segundo se distribuía por el costado occidental del río Magdalena; y el tercero tenía sus centros de producción en algunos islotes cercanos a la costa y, en menor medida, Cuba.

En Antioquia, los centros mineros atraían todo el mercado de la carne, en especial Cáceres, Zaragoza y la ciudad de Antioquia, a donde se llevaba desde dos sitios, principalmente: el primero, la villa de Caramanta, que dependía casi exclusivamente de esto para su subsistencia, pues sus pocos vecinos no tenían más beneficios y el escaso número de indios encomendados aportaba muy poco por

Colcultura, 1993-1995), 3: 148; Archivo General de la Nación -en adelante AGN(Bogotá), Colonia, Visitas de Bolivar, t. 2, fol. 600 y t. 9, fol. 55r.

${ }^{17}$ Del Río Moreno y López y Sebastián han señalado que en las Antillas era imposible comprender la existencia del cerdo sin la presencia del indio. Justo del Río Moreno y Lorenzo López y Sebastián, "Hombres y ganados en la tierra del oro: Comienzos de la ganadería en Indias", Revista Complutense de Historia de América (Madrid), 24 (1998): 32. ${ }^{18}$ AGN (Bogotá), Colonia, Visitas de Bolívar, t. 1, fol. 314r. "Relación de las cosas notables que hay en el distrito de esta audiencia de el Nuevo Reyno de Granada [ca. 1608]", en Relaciones y visitas a los Andes. Siglo XVI. Región Centro Oriental, ed. Hermes Tovar (Bogotá: Colcultura, 1995), 3: 501. 
medio del tributo. Por el río Cauca, se llevaba la carne salada en barcas, aprovechando la corriente, haciendo que el viaje fuera relativamente corto hasta los dichos centros mineros. Caramanta se mantuvo en pie solo hasta fines del siglo XVI, pues el escaso número de vecinos no pudo resistir los ataques de los indios chocoes, por lo que tomaron sus escasas pertenencias y huyeron, dejando tras de sí una tierra que contaba únicamente con carne y maíz de sobra. El heredero de la provisión de carne fue el valle de Aburrá, con varias estancias de cría y engorde de ganados porcinos y vacunos, manejados tanto por propietarios de grandes manadas como por pequeños propietarios que ponían todas sus esperanzas en que alguien les llevara sus animales hasta los centros de compra ${ }^{19}$. Asimismo, servía para que los ganados que iban desde la Gobernación de Popayán hicieran una pausa después de un largo trayecto, engordaran nuevamente y pudieran continuar su camino. Desde allí se llevaba el ganado en pie (tanto el que se criaba en el propio valle como el que hacía una etapa de tránsito), para que los mineros pudieran tener carne fresca disponible.

En la Gobernación de Popayán había varios sitios que proporcionaban marranos, tanto a los centros mineros de Antioquia -según se acaba de mencionar- como a las diferentes villas, ciudades y reales mineros de la propia gobernación, el puerto de Buenaventura e inclusive a la Audiencia de Quito. Entre los productores resaltaban las estancias de Guadalajara de Buga, las haciendas del valle de Lili, en las cercanías de la ciudad de Cali, y en especial los criaderos de la villa de San Juan de Pasto. Por último, las ciudades de Santafé de Bogotá y Tunja tenían un abasto permanente de puercos, gracias a la cantidad de población indígena encomendada que había en sus alrededores.

Cuando la piara era lo suficientemente grande, el trabajo se dividía entre criadores y porqueros: los primeros tenían a su cargo las marranas preñadas y recién paridas, así como las crías, mientras eran lechonas, y debían cuidarlas en un bohío especial, manteniéndolo tan limpio como fuera posible; los segundos se encargaban de cuidar y alimentar las manadas. En ambos trabajos era usual encargar de la labor a indios casados, ya que contaban con la ayuda de sus mujeres ${ }^{20}$.

A pesar de que en repetidas ocasiones los visitadores mandaron que el tributo tenía que ser pagado en los pueblos de indios y que de allí lo llevaran los encomenderos

19 "Mortuoria de Ana Ancerma, yndia del pueblo de San Lorenzo de Aburrá, 1627", transcripción y presentación de Gregorio Saldarriaga, Historia y sociedad (Medellín), 7 (2000): 227-237.

${ }^{20}$ Según el informe de Bartolomé Castillejo, dado en Cartagena en 1611, tanto los criadores como los porqueros podían recibir 20 pesos de plata corriente de sueldo al año, si eran casados; los solteros adultos percibían 15, y a los muchachos solo se les pagaría 10 pesos. Todo esto, en caso de que se concertaran ante la justicia. AGN (Bogotá), Colonia, Visitas de Bolivar, t. 1, fol. 372r. 
por sus propios medios, lo usual fue que los indios llevaran el maíz hasta el sitio que sus amos les señalaran, que bien podía ser su casa en la ciudad o sus estancias, donde tenían los ganados; allí depositaban el maíz en mazorca o desgranado, en uno o varios buhíos, desde donde se abastecería tanto a los criadores como a los porqueros para que lo dieran a los animales. En caso de que los alimentaran con yuca, lo cual era frecuente en la Gobernación de Cartagena, los sembradíos podían estar en las cercanías de los chiqueros, para facilitar la alimentación, y solían ser los mismos porqueros y criadores los que se ocupaban de beneficiar las sementeras. Cuando los que se dedicaban al cuidado de los puercos eran esclavos y no se disponía de indios de encomienda, el maíz podía ser cultivado por ellos o comprado a los mercaderes. Sin embargo, lo más frecuente era que los dueños de hatos ganaderos manejados por esclavos buscaran que estos realizaran todo el trabajo de manera autosuficiente, para que resultara lo más rentable posible ${ }^{21}$. Una vez estaban listos para la venta, los indios y negros conducían a los animales en piaras; se podían demorar una semana y más en ir a llevarlos hasta los centros de consumo y en volver a sus encomiendas o estancias.

En las tierras frías, principalmente Santafé, Tunja y San Juan de Pasto, los puercos podían ser vendidos en pie o bien preparados como embutidos y jamones; mientras que en las zonas calientes, lo usual era venderlos en pie o como tasajos de carne, porque no se podían hacer jamones, pues el clima no lo permitía ${ }^{22}$. Los embutidos eran parte de una economía informal de poco calado o de un ambiente familiar que trataba de aprovechar al máximo el sacrificio, convirtiendo el evento en una celebración en la cual participaban todos los miembros de la familia y los sirvientes $^{23}$. Así, se establecieron dos tipos de producción y de consumo del cerdo: en la tierra fría, el patrón ibérico encontró más acogida, gracias a las posibilidades climáticas, lo cual además se reforzó con una mayor panificación de trigo y la presencia de carneros ${ }^{24}$. Por su parte, en las tierras calientes se desarrolló un patrón

\footnotetext{
${ }^{21}$ A comienzos del siglo XVII, Francisco de Montiel tenía una estancia dedicada a la cría de ganados en una isla en frente del golfo de Urabá, con la cual abastecía a Cartagena. Fray Pedro Simón, Noticias historiales de las conquistas de Tierra Firme en las Indias Occidentales ([¿1628?]; Bogotá: Banco Popular, 1981-1982), t. 6, parte 3, cap. 61: 495 y ss.

22 Bernardo Vargas Machuca, Milicia y descripción de las Indias (Bogotá: CESO; Biblioteca Banco Popular, 2003), 266.

23 Archivo Histórico de Antioquia -en adelante AHA- (Medellín), Gobernación de Antioquia, Mortuorias, t. 220, doc. 5169; Gregorio Saldarriaga, "Redes y estrategias femeninas de inserción social en tierra de frontera: tres mujeres desarraigadas en Antioquia, siglo XVII", en Las mujeres en la construcción de las sociedades iberoamericanas, eds. Pilar Gonzalbo y Berta Ares (México y Sevilla: El Colegio de México; Escuela de Estudios Hispano-Americanos, 2004), 141-161.

24 “"...] llegan a Santa fe do pierden el enojo con comprar a diez panes por un real y un carnero por 4 reales", "Relación de las cosas notables que hay en el distrito de esta
} 
propio, que si bien tenía raíces ibéricas, en su proceso se mostró original y novedoso, pues el cerdo comenzó a estar en todas las comidas permanentemente como la base misma, en su mayor parte fresco y acompañado de panes de maíz y yuca. Esto se hizo más evidente en la Gobernación de Cartagena y las Antillas, hecho nada gratuito - pues eran los sitios donde más producción se necesitaba para el abasto de las naves- que terminó por afectar el consumo y las prácticas alimentarias de una área geográfica bastante amplia.

\section{Un cerdo sabroso y saludable}

A comienzos del siglo XVII, León Portocarrero, judaizante gallego, hizo una descripción del Perú para unos correligionarios en Holanda. En ella incluyó además las regiones que mediaban entre el Perú y Europa, o que eran adyacentes a tal virreinato. Al referirse a Cuba, señaló algo que también era válido para Cartagena: "Críanse aquí grande cantidad de puercos, ques carne muy sana, y todas las naos cargan mucho para que coma la gente, en conclusión, aquí se faz bon matalo[ta]je $[\ldots]^{, 25}$.

Que un judío escribiese (o escriba aún hoy, en caso de ser practicante) que una carne condenada por el Levítico como impura era sana resulta impactante ${ }^{26}$, tanto que podría llevar a pensar que quien redactó la descripción no era judío. Sin embargo, las expresiones y fórmulas utilizadas indican que sí lo era, tal como lo ha demostrado Boleslao Lewin, editor y prologuista de la obra ${ }^{27}$. Igualmente, se puede pensar que era un judaizante que había olvidado ese precepto alimentario o no lo tenía claro; pero ningún judaizante - por lo menos de los que fueron detenidos por el Santo Oficio- había olvidado las ceremonias que tenían que ver con las prohibiciones y los preceptos alimentarios impuestos por su fe y, por el contrario, trataban por todos los medios de cumplirlos ${ }^{28}$. Queda la posibilidad de entender tal afirmación como producto de un lapsus social: repitió la información que tenía y

audiencia de el Nuevo Reyno de Granada [ca. 1608]", en Tovar, Relaciones y visitas, 3: 496.

${ }^{25}$ [¿León Portocarrero?], Descripción del virreinato del Perú (Rosario: Universidad Nacional del Litoral, 1958), 123.

${ }^{26}$ Para un análisis sobre la impureza en el Levítico, véase Mary Douglas, Purity and Danger. An Analysis of Concepts of Pollution and Taboo (Harmondsworth: Penguin Books, 1970), 63 y ss.

${ }^{27}$ Es extraño que Lewin no hiciera ninguna mención a lo que se anotaba sobre la carne de cerdo en el texto. Seguramente para él fue un hecho intrascendente, que en realidad no lo es, pues el peso de esta prohibición era (y sigue siendo) muy fuerte entre las comunidades judías o judaizantes, tanto que es un punto de unión, cohesión e identidad para ellas.

${ }_{28}$ Maria Aparecida de Araujo Barreto Ribas, $O$ pão do outro: alimentação e alteridade no Brasil colonial (1500-1627), (Disertación de maestría en historia del programa interinstitucional UFF/Unioeste, Niterói, 2002), 67. 
que compartía en el medio en que estaba, pero se equivocó al poner tal mensaje para los destinatarios de la relación ${ }^{29}$. Al manejar dos niveles culturales diferentes, fue incapaz de abandonar la esfera indiana y olvidó hacer la traducción correspondiente para que fuera comprensible a sus interlocutores judíos.

Ahora bien, que sea o no un lapsus, solo importa para demostrar hasta qué punto los judaizantes estaban en un medio en el que los cerdos eran casi omnipresentes y se proyectaban como sombras sobre ellos, hasta lograr que adoptaran, aunque fuese momentáneamente, las expresiones, ideas y explicaciones que había en torno a las bondades de su carne.

Pasada la primera mitad del siglo XVI, la idea de las ventajas de esta carne en Cartagena y las Antillas ${ }^{30}$ se transformó drásticamente, por lo que se pensaba no solo de su sabor, sino de sus cualidades. Alrededor de 1577, el viajero y comerciante italiano Francesco Carletti pasó por Cartagena, en donde sufrió una enfermedad por la cual lo purgaron. Al ver el plato que le dieron posterior a su medicamento, su sorpresa fue tanta que no pudo menos que registrarla en sus Razonamientos:

[...] en vez de pollos y gallinas que nosotros debíamos comer como enfermos, nos permitía el médico y ordenaba que comiéramos carne de cerdo fresca, la cual en aquella tierra, para no decir mentiras, es en verdad tan excelente al gusto cuanto se pueda imaginar, y así pretenden que es muy buena para la salud por estar hecha en país muy húmedo y muy caliente y nutrida además con buenas cosas y piensos de aquella tierra ${ }^{31}$.

Como él, el dominico y luego pastor protestante Thomas Gage, casi sesenta años después, en su viaje de regreso a Europa, pasó por Cuba, donde fue purgado:

[...] cuando mi purga hubo hecho operación y yo esperaba que me trajesen un pedazo de carnero o gallina, o alguna otra suerte de carne nutritiva, mi médico ordenó se me diese un trozo de puerco asado, lo que rehusé creyendo me haría daño en el estado en que me hallaba, diciendo al médico que esto era contra la práctica de todas las naciones, porque la calidad de esta carne era de soltar el vientre. Mas él me respondió que el puerco hacía todo lo contrario en aquel lugar de lo que hacía en otras partes, y que yo

${ }^{29}$ Para un análisis de un lapsus histórico, véase Carlo Ginzburg, Ojazos de madera. Nueve reflexiones sobre la distancia (Barcelona: Península, 2000), 223 y ss.

${ }^{30}$ Especialmente en Cuba, Jamaica y Martinica, no así en Santo Domingo, donde sí abundaba la carne de res.

${ }^{31}$ Francesco Carletti, Razonamientos de mi viaje alrededor del mundo (1594-1606), estudio preliminar, traducción y notas de Francisca Perujo (México: Instituto de Investigaciones Bibliográficas, UNAM, 1976), 32. 
debía comer de lo que me ordenaba, asegurándome que no me haría ningún daño ${ }^{32}$.

Como estos dos viajeros, muchos otros dejaron testimonios de las bondades del cerdo caribeño y de las diferencias que existían con los demás, idea que era incluso compartida por los colonos franceses, habitantes de las Antillas ${ }^{33}$. Es casi imposible determinar si la mejoría en el sabor entre el marrano caribeño y el europeo (o incluso el andino) correspondía a causas objetivas o subjetivas. A riesgo de parecer en exceso conciliador, hay que decir que se dieron las dos causas: en las primeras se encuentra el tipo de alimentación que, entre el maíz, la yuca y algunos frutos silvestres, proporcionaba a los puercos un sabor especial, libre de sobrantes o comidas dudosas, tal y como podía pasar cuando no se disponía de tales productos. A esto se puede contraponer la idea de que no habría mejor alimento para estos animales que las bellotas de los encinos, que comían en los campos de Jabugo o en otros de España. Ante lo cual, hay que responder con la parte subjetiva: el aumento de producción de carne en las Indias y en el Caribe -en este caso- permitió que la gente pudiera acceder a partes del cerdo que antes no podían consumir continuamente de esa manera; al no poder hacerse jamones en tierra caliente, las piernas de los cerdos quedaron liberadas al consumo directo y fresco, y regalaron sabores ocultos bajo las curaciones y salazones. Las partes que antes iban al puchero para ser compartidas por muchos, ahora podían ser consumidas por un comensal, quien se deleitaba con la totalidad de la pieza; pedazos irreconocibles que se destinaban antes a las empanadas formaron en ese momento un todo sabroso, que permitía al comensal sentirse el dueño de su sabor. Así, la cantidad y la disponibilidad permitieron una individualización del producto, en la cual el comensal tenía acceso a un trozo reconocible que podía comer repetidamente y encontrar en él -y en los diferentes cortes que se hicieran- una cualidad específica que se acentuaba y profundizaba a medida que más se ingería. La ingestión

\footnotetext{
${ }^{32}$ Gage, Nueva Relación, parte 4, cap. 13: 483-484. Otra referencia a tal experiencia se encuentra en Ibídem, parte 2, cap. 5: 197; el cosmógrafo real López de Velasco anotó lo mismo para Cartagena "cuya carne [del cerdo] se da por sana á los enfermos". Juan López de Velasco, Geografía y descripción universal de las Indias, ed. Marcos Jiménez de la Espada (Madrid: Atlas, 1971), 195.

${ }^{33}$ Juan Méndez Nieto, Discursos medicinales compuestos por el licenciado Juan Mendez Nieto, que tratan de las maravillosas curas y sucesos que dios nuestro señor a querido obrar por sus manos, en cinquenta años que a que cura, ansi en españa, como en la ysla española, y rreino de tierra firme, [...] En cartagena indiana, año de 1607 y de la hedad del autor 76. [...] (Salamanca: Universidad de Salamanca; Junta de Castilla y León, 1989), lib. 2, discurso 20: 286; Ocaña, A través de la América, cap. 2: 42; Simón, Noticias historiales, t. 6, parte 3, cap. 63: 505; Labat, Viajes a las islas de la América, parte 5, cap. 1: 185; Joannes de Laet, Mundo nuevo o descripción de las Indias occidentales (Caracas: Universidad Simón Bolívar; Instituto de Altos Estudios de América Latina, 1988), lib. 1, cap. 4: 69 .
} 
reiterada permitía decodificar características y asumirlas como virtudes. Antes, como parte de un todo más amplio (guiso, menestra, empanada) el puerco quedaba integrado y era difícil asignarle unas características propias; pero cuando pudo emerger en solitario, sus características especiales lucieron como defecto o como virtud; en este caso prevaleció lo segundo. Es claro que en Europa y en España había grupos que podían darse el lujo de acceder a piezas de puerco tal y cómo se hacía en las Indias, pero allá era una experiencia que no cubría a un sector amplio, y que tampoco correspondía al nivel social de quienes dejaron testimonios sobre la calidad del cerdo.

De otro lado, estaba el porqué de la creencia en que el chancho caribeño era saludable. Parte de la respuesta es necesario buscarla en las ausencias, más que en las presencias. La falta de otros tipos de carnes reputadas como sanas (p. ej. el carnero) hizo que la única carne abundante y fresca sirviera en las medicaciones que se daban. Así, el cerdo pudo ocupar un espacio en la estructura alimentaria de la salud dietética, porque el campo quedó desocupado y no había contendientes serios a ocuparlo. Sin embargo, tal respuesta solo puede ser parcial; a fin de cuentas, existían suficientes gallinas, que eran entregadas por las encomiendas y que bien hubieran podido ocupar ese puesto. Por lo tanto, el resto de la respuesta hay que buscarla en el cambio de la percepción del sabor: el aumento del consumo permitió encontrar o crear virtudes desconocidas hasta ese momento. Una dieta basada en la carne del cerdo y una cocina que usaba como grasa ${ }^{34}$ principal la extraída de este animal fueron los elementos constitutivos de esta sociedad, que los encontró importantes, los ensalzó y los convirtió en la clave de su salud. No es solo pensar que hicieron virtud de la necesidad, sino ver cómo un cambio fundamental en la dieta, que incluía el abandono de otros aceites, la exclusión de varios animales y la producción e ingestión de un animal en cantidades mayores de las habituadas, llevaron a una región geográfica amplia a construir su identidad gustativa y médica con parámetros novedosos, aunque insertos en una estructura hispánica.

El proceso fue especialmente visible para los que eran ajenos a estas sociedades que se venían construyendo en el marco geográfico de la zona caribeña, y, por la extrañeza que les causaba, de ello dejaron testimonio. Sin embargo, este cambio se vio a la luz de estructuras de pensamiento europeas y lo pudieron comprender cabalmente, en parte, porque esas mismas sociedades así lo habían entendido: la primera explicación tenía que ver con los cambios que los cuerpos experimentaban al mudar de sitio, pues se pensaba que el influjo de la tierra y de las estrellas

\footnotetext{
${ }^{34}$ Sobre el uso de grasas en las cocinas europeas, veáse Flandrin, "Le goût et la nécessité",
} 378. 
producía en los seres efectos especiales que transformaban sus calidades ${ }^{35}$. Parte de la explicación pasaba también por la forma en que las cualidades de la tierra influía en los tipos de alimentos que los ganados consumían, lo cual los transformaba y alteraba las características conocidas en el Viejo Mundo. La teoría de los humores seguía siendo determinante en la Edad Moderna, y con ella se explicaban los cambios producidos por lo que hoy llamaríamos la transculturación ${ }^{36}$.

Las necesidades marítimas hicieron que en Cartagena y las Antillas se establecieran nuevos patrones de producción, que terminaron por crear otros en el campo de la alimentación. Recorridos que unían los puertos del Caribe, y otros que iban de España a las Indias, fueron marcando las huellas de una alimentación que se diferenciaba tanto de la europea como de la del interior del continente; por eso la sorpresa era tanto de los europeos recién llegados (Ocaña, Carletti) como de aquellos que habían vivido por años en otras zonas de las Indias (Gage, fray Pedro Simón). Al alejarse de los esquemas tradicionales, la experiencia porcina caribeña fue novedosa, aunque siguiera ciertas líneas de continuidad de la tradición ibérica: gusto, sabor, identidad y distinción, pero todo en nuevas perspectivas, dimensiones y magnitudes, y, sobre todo, concepciones de la vida y la salud.

\section{Entre el agua y la tierra: los anfibios americanos ${ }^{37}$}

\footnotetext{
${ }^{35}$ Como ejemplo de este pensamiento se puede recordar al cosmógrafo real Juan López de Velazco, quien afirmó: "Los españoles que pasan á aquellas partes y están en ellas mucho tiempo, con la mutación del cielo y del temperamento de las regiones aun no dejan de recibir alguna diferencia en la color y calidad de su persona; pero los que nacen dellos, que llaman criollos, y en todo son tenidos y habidos por españoles, conocidamente salen ya diferenciados en la color y tamaño, porque todos son grandes y la color algo baja declinando á la disposición de la tierra; [...]: y no solamente en las calidades corporales se mudan, pero en las del ánimo suelen seguir las del cuerpo, y mudando él se alteran también [...]". López de Velazco, Geografía y descripción, 11-12 (resaltado del autor). Un razonamiento similar se puede encontrar en Fernández de Oviedo, Sumario, cap. 11: 105; Carletti, Razonamientos, tercer razonamiento, 39.

${ }^{36}$ Juan Huarte de San Juan, Examen de ingenios para las ciencias, ed. Esteban Torre (Madrid: Editora Nacional, 1976), cap. 2: 87; “y así pretenden que es muy buena [la carne de cerdo] para la salud por estar hecha en país muy húmedo y muy caliente y nutrida además con buenas cosas y piensos de aquella tierra"; Carletti, Razonamientos, tercer razonamiento, 32; Rudy Steinmetz, "Conceptions du corps a travers l'acte alimentaire aux $\mathrm{XVII}^{\mathrm{e}}$ et XVIII ${ }^{\mathrm{e}}$ siècles", Revue d'histoire moderne et contemporaine (París), 35 (eneromarzo 1998): 11.

${ }^{37}$ Es claro que los animales a los que me referiré no son anfibios en el sentido de la clasificación zoológica. Sin embargo, sí lo son en el sentido amplio de la palabra, porque son capaces de vivir tanto en el agua como en la tierra, y así fueron entendidos en la edad moderna, cimentados en parte en la tradición. "Anfibios son unos géneros de peces así llamados porque viven tanto en la tierra como en el agua. Anfi en griego significa uno y otro, esto es, que viven tanto en el agua como en la tierra; tales son las focas, cocodrilos,
} 
Buena parte de la experiencia previa americana se fraguó en las Antillas y desde allí algunas voces pasaron a la tierra firme para designar especies animales y vegetales, así como usos y costumbres que los españoles aprendieron en ellas y buscaron implantar en otras tierras. Esto también pasó con los anfibios americanos, pues los nombres hicotea, iguana, manatí y caimán son todos provenientes de estas islas; las primeras sorpresas ante estas nuevas naturalezas se dieron allí, aunque se repitieron una y otra vez hasta fines del XVI en la tierra firme.

Los dos animales que más sorpresa causaron fueron la iguana y el manatí, mientras que las hicoteas (o tortugas) y los caimanes tuvieron el camino allanado por las especies similares que habitaban el Viejo Mundo y que les servían de referentes, bien fuera a través de la autoridad de Plinio, de San Isidoro de Sevilla o por la experiencia directa que tuvieran con los quelonios o galápagos, aunque unos y otros estuvieron ante los ojos de los españoles en un estado de difícil definición, por su trasegar entre agua y tierra.

\section{Tiempo de sorpresas}

El manatí y sus características impactaron con fuerza a los conquistadores. Los sorprendió ese animal que vivía en el agua y salía de ella para alimentarse, y que además combinaba en su ser características ajenas a los peces: carecía de escamas y tenía cuero, se reproducía y alimentaba a sus crías bajo los patrones de los mamíferos, contaba con aparatos reproductores similares a los humanos, le crecía vello en algunas partes del cuerpo, y su cabeza era similar a la de un becerro o un buey $^{38}$. Incluso Anglería escribió que "es una especie de monstruo desconocido en nuestros mares" ${ }^{\prime 39}$. Podría pensarse que su monstruosidad residía en el hecho de tener infinitas verrugas o un cuero que desafiaba las flechas, como pensaba Anglería que sucedía; pero creo que no era esto lo que hacía del animal un monstruo. Nuestros ojos ya no se sorprenden con el manatí de la misma manera que antes, ni nos resulta un monstruo, tal vez porque la palabra ya no significa lo mismo que antes. Un historiador tan brillante como Musset afirmó: "Por supuesto

hipopótamos, o sea, caballos fluviales". San Isidoro de Sevilla, Etimologías, trad. Luis Cortés y Góngora (Madrid: Biblioteca de Autores Cristianos, 1951), lib. 12, cap. 6: 302.

38 “....] extraño genero de pescado, si pescado se puede llamar animal que pare vivos sus hijos, y tiene tetas y leche con que los cría, y pace yerba en el campo, pero en efecto habita de ordinario en el agua, y por eso le comen por pescado, aunque yo cuando en Santo Domingo lo comí un viernes, cuasi tenía escrúpulo, [...] porque en el color y sabor no parecían sino tajadas de ternera, y en parte de pernil”. José de Acosta, Historia natural y moral de las Indias (México: Fondo de Cultura Económica, 1940), cap. 15: 179; Tomás López Medel, Tratado de los tres elementos (Madrid: Alianza, 1992), cap. 8: 92 y ss.

${ }^{39}$ Pedro Mártir de Anglería, Décadas del Nuevo Mundo (México: Porrúa, 1964), 1: 361. 
el manatí no es en sí una criatura fabulosa" ${ }^{\text {, }}$, olvidando que tal vez no haya animal en sí que lo sea o que no lo sea (según como se mire), y que lo interesante es por qué llegó a llamar tan poderosamente la atención de unos nuevos observadores. Uno de los puntos que tanto atrajo la curiosidad de los conquistadores fue la forma como vieron representada en el manatí la combinación de elementos que parecían irreconciliables: vivía en el agua a pesar de poseer ciertas características físicas que lo hacían más cercano a la tierra; su cabeza no correspondía -a ojos de los españoles-a sus extremidades y su cuero (semejante solo al de los delfines) poseía pelo; además estaba la perturbadora presencia de genitales semejantes -siempre bajo la óptica española- a los de los humanos. En el Tesoro de la lengua castellana, la definición de monstruo dice: "Es cualquier parto contra la regla y orden natural"; así, el manatí quebrantaba unas y otras, pues mezclaba en su ser lo que no debía ser mezclado.

Como el manatí, la iguana también causó sorpresa por sus formas, aunque sin provocar tanto estupor. En parte, porque existían más referentes que permitieron comprender este animal (sierpes, lagartos, salamandras), y simplemente había que tratar de ajustarlos para tener una imagen más o menos clara ${ }^{41}$. No obstante, como en el caso del manatí, hubo un punto que hacía dudar de la naturaleza de este animal: "No sé determinar si es carne o pescado, ni ninguno lo acaba de entender, porque vemos que se echa de los árboles al agua y se halla bien en ella; y también, la tierra adentro" ${ }^{42}$. Este trasegar que caracteriza a los anfibios resultaba un problema clasificatorio, pues implicaba que estos seres se movían entre dos partes del mundo que habían sido divididas por dios en el mito de creación bíblico; al ir del agua a la tierra contravenían el orden divino. Además, como no pertenecían por completo ni a una ni a la otra, tampoco parecían estar dentro del plan divino que le asignaba a cada animal su lugar en el mundo (el aire, el agua o la tierra) ${ }^{43}$. ¿Es plausible pensar que eran estas ideas las que se encontraban tras la sorpresa española? Estas eran parte de su bagaje cultural y por lo menos en un caso se hizo

\footnotetext{
${ }^{40}$ Alain Musset, El agua en el valle de México, siglos XVI-XVIII (México: Pórtico de la Ciudad de México; Centro de Estudios Mexicanos y Centroamericanos, 1992), 28.

41 "Por los árboles que están juntos a los ríos hay una que se llama iguana, que parece serpiente; para apropiarla, remeda en gran manera a un lagarto de los de España, grande, salvo que tiene la cabeza mayor y más fiera y la cola más larga; pero en el color y parecer no es ni más ni menos." Cieza de León, Crónica del Perú, parte 1, cap. 9: 18.

${ }^{42}$ Ibídem. También Fernández de Oviedo, en Sumario, cap. 6: 73, escribió: "Ni está averiguado si son animales o pescado, porque ellas andan en el agua y en los árboles y por tierra".

${ }^{43}$ Génesis 1: 26. Douglas ha mostrado que en las concepciones del Levítico es impuro todo aquello que combinaba dos órdenes, que fuera ambiguo o anómalo en cuanto al orden establecido por dios, y que la santidad de las cosas dependía de que mantuvieran una unidad, libres de mezcla. Douglas, Purity and Danger, 26.
} 
explicito $^{44}$, y si bien el principio bíblico de la separación entre el agua y la tierra puede ser una manifestación de un problema clasificatorio humano más profundo que no se limita solo a la tradición judeocristiana -como ya lo ha mostrado Douglas $^{45}$ - creo que la línea de continuidad en el caso español es bastante clara.

Ahora bien, hubo otro tipo de características que causaban entre los españoles dudas relativas a su carne y sus sabores, pues una y otros se acercaban más a la tierra que al agua. La iguana era comparada en ocasiones con el conejo, en otras con la gallina y en otras con los faisanes, perdices y pavos ${ }^{46}$. Por su parte, el manatí fue comparado con la ternera y el cerdo ${ }^{47}$; con su carne se preparaban cecinas y tocinetas, y se adobaba como atún. Si bien la duda acerca de su naturaleza y su carne pesaron hasta fines del siglo XVI, desde el principio se decidió que ambos eran peces y por tales los consumieron. Las vacilaciones que surgían de tanto en tanto entre individuos recién venidos o muy escrupulosos en cuestión de abstinencias servían para recordar a la comunidad establecida que estos animales eran especiales y que no correspondían a nada de lo que hubiesen conocido con anterioridad $^{48}$. Tal vez por sus naturalezas inciertas o por la forma en que mediaban entre el agua y la tierra, sus carnes adquirieron una cualidad especial que no he visto que se le asignara a ninguna otra: eran tenidas por carnes sanas, excepto para aquellos que hubiesen contraído bubas, pues estas carnes avivarían los dolores y las descubrirían en quienes las tuvieran ${ }^{49}$. Seguramente, operó un principio de magia simpática: como estos animales tenían la posibilidad de sumergirse en el agua y salir a tierra, su carne podía sacar a flote lo oculto.

\section{Abastos, consumo y gusto}

\footnotetext{
${ }^{44}$ López Medel, Tratado de los tres elementos, cap. 6: 36.

${ }^{45}$ Mary Douglas, "Las estructuras de lo culinario", en Alimentación y cultura. Necesidades, gustos y costumbres, comp. Jesús Contreras (México: Alfaomega, 2002), 174.

${ }^{46}$ Cieza de León, Crónica del Perú, parte 1, cap 9: 18; Fernández de Oviedo, Sumario, cap. 6: 73; Bartolomé de Las Casas, Historia de las Indias (México: Fondo de Cultura Económica, 1981), cap. 43: 217; Anglería, Décadas del Nuevo Mundo, 1: 157.

${ }^{47}$ Acosta, Historia natural, cap. 15: 179; Vargas, Milicia, 80; Laet, Mundo Nuevo, lib. 1, cap. 4: 70

${ }^{48}$ En Europa hubo un especie de antecedente, pues Inglaterra, en los albores de la Edad Moderna se cazó el castor hasta su extinción para consumirlo como pescado en las épocas de abstinencias religiosas. Maggie Black, The Medieval Cookbook (Londres: British Museum Press, 1996), 11.

49 "Descripción de la ciudad de Tamalameque en la Gobernación de Santa Marta, 5 de marzo de 1579", en Tovar, Relaciones y visitas, 293; "Relación de la conquista de los carares [9 de mayo de 1601]", en Ibídem, 440; Fernández de Oviedo, Sumario, cap. 6: 74; Laet, Mundo nuevo, lib. 1, cap. 9: 88-89.
} 
He centrado la mirada en el manatí y la iguana porque estos fueron los dos anfibios que más sorpresa causaron entre los españoles. Ahora trataré de mostrar la forma como, además de la tortuga y el caimán, estos se integraron a las dietas de las nuevas sociedades que se estaban conformando; los mecanismos que tuvieron para abastecerse de tales animales; los productos obtenidos, y las valoraciones que se merecían estos productos.

El hábitat de los animales anfibios americanos estaba en las zonas templadas y cálidas, en las costeras y en las ribereñas del río Magdalena. Y allí mismo fueron los sitios en donde más se consumieron sus carnes y derivados; se puede ver cómo hubo gustos diferenciados entre las tierras altas y frías y las bajas y cálidas; esto no se puede reducir simplemente a una explicación climática. Más bien, habría que pensar en una clave tripartita, en la que la primera premisa señala el tipo de villas y ciudades que se levantaron en el entorno en que vivían estos animales, pues eran puertos abiertos que veían el continuo trasegar de individuos que necesitaban ser alimentados; o bien, estos asentamientos estaban en la zona de confluencia de regiones mineras que necesitaban los productos extraídos de estos animales (principalmente carne y aceite). Ahora bien, para la segunda parte de la clave se tiene que contar con la mano de obra indígena de la zona: como parte de sus prácticas prehispánicas, los pueblos indigenas se habían dedicado a cazar manatíes y caimanes, así como a montear tortugas e iguanas para su propio beneficio y, para ello, a través del tiempo, desarrollaron saberes que les indicaba los tiempos y los métodos para realizar tales actividades. Con la llegada de los conquistadores, los beneficios del trabajo se encausaron hacia ellos y la escala en la cual debían realizar su trabajo los aborígenes aumentó considerablemente, así como pudo cambiar en algo su trabajo, por la introducción de ciertos elementos nuevos, como los arpones de acero y los machetes. De esta manera, los españoles se apropiaron de un trabajo tradicional indígena en beneficio propio y aprendieron lo necesario para hacerse con la explotación. Y esto lleva a la tercera parte de la respuesta: los españoles y las sociedades en construcción supieron aprovecharse de estos mantenimientos, los insertaron dentro de sus esquemas gustativos y les hallaron virtudes o defectos con los cuales los ubicaron en una escala de valores, que o bien los puso en la base misma de su dieta o bien los llevó a apartarlos de su horizonte alimentario y los estigmatizaron como comida de cierto tipo de gente. A continuación, trataré de desarrollar por aparte cada una de estas claves, para tratar de armar todas las piezas del rompecabezas.

Desde mediados del siglo XVI, Cartagena se erigió como un puerto principal en el cual atracaban los barcos cargados de esclavos, los que traían mercancías para el Nuevo Reino o los que simplemente estaban de paso en su camino hacia otros puertos, como el de Nombre de Dios (el de desembarco de las mercancías destinadas al Perú). Allí, como en otros puertos caribeños (en especial en La Habana), buena parte de la producción de alimentos de la región colindante se puso 
en función del puerto y de las embarcaciones que atracaban. La magnitud de la producción necesaria para el puerto incidió notablemente en el tipo de alimentación que se consumió en la ciudad y en buena parte de la gobernación, sin olvidar que se producía lo que era más redituable para la tierra y lo que se había mostrado exitoso. Como ejemplo, se puede pensar en la obligación que algunos encomenderos impusieron a los indios tributarios para que fabricaran cazabe a finales del siglo XVI, pues había necesidad de un producto que remplazara al bizcocho. Los indios protestaron, pues esta actividad era muy dispendiosa y no hacía parte de su experiencia cultural: en tiempos prehispánicos no se elaboraba ni consumía esta panificación en la banda occidental del río Magdalena, a la cual corresponde Cartagena. En las visitas de comienzos del XVII, se prohibió emplear a los indios en ello, con lo cual comenzó a ser fabricada por los esclavos en algunas estancias. El cazabe fue un alimento que encontró poca acogida en el gusto de los españoles, que lo consumían en momentos de necesidad, como en los viajes o en estadías en alguna cárcel ${ }^{50}$. Pero la presencia del cazabe terminó por penetrar el gusto de un segmento de la sociedad: el de los esclavos y negros libertos, precisamente aquellos a quienes se les encargó la producción. Este es solo un ejemplo para mostrar cómo la producción de alimento requerida por el puerto influía en la dieta cotidiana y en el gusto de la sociedad que habitaba en la ciudad de Cartagena y sus alrededores.

Parte del bastimento que se necesitaba en el puerto era de carne de tortuga. Aunque nunca llegaba a competir en cantidad con la de cerdo, proporcionaba algo de variedad, pues su sabor se asemejaba, para algunos, al de la carne de vaca ${ }^{51}$. Cartagena no fue el único sitio donde se consumía tortuga, pues en las villas y ciudades de las riberas del río Magdalena, especialmente en Tamalameque y Mompox, también había un consumo de estos animales. Tales asentamientos $n$ oeran comparables con Cartagena, pues ni sus vecinos ni su movimiento comercial igualaban al de esta ciudad; asimismo, era comparativamente más baja la producción y consumo de tortuga. Las provisiones de tortuga se destinaban a la venta de quienes navegaban por el río Magdalena, que era la principal arteria económica y de transporte del Nuevo Reino de Granada ${ }^{52}$.

\footnotetext{
${ }^{50}$ Ana María Splendiani y otros, Cincuenta años de inquisición en el tribunal de Cartagena de Indias 1610-1660 (Bogotá: Instituto Colombiano de Cultura Hispánica; Ceja, 1997), 3 : 348.

${ }^{51}$ Portocarrero, Descripción del virreinato, 122; para Gage, las tortugas sabían a ternera, a gallina y, saladas, a cecina. Gage, Nueva relación, parte 1, cap. 4: 51; Ocaña, A través de la América, cap. 2: 39.

52 Según una relación de ciudades de 1650 (ca.), Cartagena tenía aproximadamente 800 vecinos, mientras que Mompox contaba con 200 y Tamalameque tenía cinco o seis, Archivo General de la Nación (México), Inquisición, vol. 1482, fols. 126 y ss. En Cartagena, los que emprendían viaje por el río Magdalena también contaban con comprar
} 
Para los habitantes de las ciudades abastecidos con tortuga, el consumo representaba una alternativa para los días de abstinencia, lo cual hacía que la demanda aumentara en esos días, especialmente en la cuaresma. Es muy probable que esta festividad cristiana coincidiera con un período tradicional de caza que funcionaba desde tiempos prehispánicos, vinculado al cambio de temporadas, pues era la antesala de la época de lluvias en el Nuevo Reino.

Los encargados de conseguir las tortugas eran principalmente indios. Para hacerlo, recurrían a dos métodos: el primero era la pesca con redes; una vez atrapadas, las ponían en las canoas y luego las enviaban a sus encomenderos. Sin embargo, por las veces que aparece esta práctica en las fuentes, se puede pensar que era muy reducida y dependía del azar de encontrar estos animales mientras se realizaban otros tipos de pesca. La segunda era la montería. Para ello, los indios iban hacia las zonas boscosas cercanas a ríos o lagunas en las cuales sabían que había tortugas y allí comenzaban a rastrearlas; una vez ubicadas, podían elegir entre ir a agarrarlas directamente, en caso de que estuvieran en sitios accesibles, o prender fuego a la zona, si eran escurridizas. Aunque estas actividades podían desarrollarse a cualquier hora, era mejor realizarlas con luz diurna, preferiblemente a mediodía ${ }^{53}$. Una vez capturadas, era común agrupar las tortugas en hilos (cinco por cada hilo), lo que les permitía llevar la cuenta con cierta facilidad. Los indios las llevaban en barquetas hasta la casa del encomendero ${ }^{54}$. Como este obligaba a dar las tortugas como parte del tributo, los indios recibían poco o nada por cien o más tortugas que cada pueblo solía dar en tiempo de cuaresma. Por su parte, algunos de los doctrineros que iban a los pueblos cercanos a la villa de Tolú pedían a los indios que los viernes les trajeran un par de tortugas para comer; tampoco les daban nada, pues pensaban que era parte de su pago ${ }^{55}$.

Es difícil determinar el proceso de adaptación y cambio que se dio con la tortuga en el gusto de los españoles entre los siglos XVI y XVII. Incluso con las fuentes consultadas, no es posible precisar varió el abastecimiento en este tiempo, aunque es factible pensar que, a medida que las encomiendas dejaban de estar en manos de los vecinos y pasaban a la Corona, el negocio de venta de las tortugas debió quedar directamente en los indios, y que progresivamente más esclavos, libertos, mestizos o blancos pobres se dedicaron a esta actividad.

En las fuentes sí se observa la forma como los españoles aprendieron a sacarle provecho: para llevarla en el viaje, la carne de tortuga era cortada en tiras largas,

tortugas para el viaje, que podían valer entre un real y medio y dos reales. AGN (Bogotá), Colonia, Visitas de Bolivar, t. 2, fol. 272.

${ }^{53}$ Ibídem, t. 5, fol. 559v.

${ }^{54}$ Ibídem, t. 6, fol. 189r.

${ }^{55}$ Ibídem, t.10, fol.190v. 
que se salaban y secaban al viento y al momento de consumirlas se las asaba con un poco de ajo, con lo cual la gente de mar quedaba satisfecha y encontraba la carne más saludable, incluso por encima de la del cerdo ${ }^{56}$. Cuando podían tenerla fresca, tanto los marineros como los habitantes de Cartagena contaban con la posibilidad de prepararla en potajes o sopas, que se adobaban con varias especias, bien sea del nuevo o del viejo continente. Es difícil saber qué tanta tradición indígena hacía parte de estas preparaciones, pero es factible pensar que las que se hacían con tortuga correspondían a las que los españoles hubieran hecho con pedazos de vaca o ternera, pues la semejanza en el corte y en el sabor así lo posibilitaban; la semejanza llegó a tal punto que en las carnicerías en que se vendían, se pesaba su carne "por libras o arreldes, ansí como puerco, carnero o vaca" $"$. Aunque lo más acertado sería pensar que la confluencia de tradiciones, saberes y gustos fue creando tipos de preparaciones, que si bien seguían líneas de continuidad de una y otra tradición y podían corresponder a formas arquetípicas de platos, en sí mismas eran novedosas y lograron calar en el gusto de los diferentes sectores de la sociedad.

Como se mencionó anteriormente, la tortuga fue considerada como pescado, por lo cual podía ser consumida en días de abstinencia, especialmente en cuaresma. Sin embargo, su apariencia y sus preparaciones recordaban más a la carne, lo cual podía seguir creando escrúpulo en algunos cuantos que, como Acosta, no se terminaban de convencer de que los anfibios fueran realmente pescados ${ }^{58}$. De otro lado, estaban los judaizantes, ques por razones religiosas tenían prohibido comer peces sin escamas, y los que pensaban que no era permitido comer peces con sangre en tiempo de cuaresma ${ }^{59}$.

\section{El manatí: aceite y carne}

El manatí fue un producto clave de la economía de los asentamientos humanos en el río Magdalena, a la altura de su encuentro con el río Cauca. Entre los más importantes en este comercio estaban Tamalameque y Mompox, dos villas que servían como puerto de bogas. Su principal aprovechamiento era la manteca que extraían de este animal. Esta servía para las lámparas y para la preparación de comidas, aunque su uso mayoritario se enfocó en el primer uso. Las botijas en las que iba el aceite se destinaban para los reales, villas y ciudades que mantenían contacto con Mompox y Tamalameque: destacaban Remedios, Zaragoza, Cáceres y

\footnotetext{
${ }^{56}$ Gage, Nueva Relación, parte 4, cap. 13: 484. Los filibusteros, corsarios y piratas de todas las naciones que desarrollaban su trabajo en la zona de las Antillas también la encontraban sabrosa y saludable, como se puede leer en Exquemeling, Historias de Piratas, 38.

${ }^{57}$ López Medel, Tratado de los tres elementos, cap. 8: 95.

${ }^{58}$ Acosta, Historia natural, cap. 15: 79.

${ }^{59}$ Splendiani, Cincuenta años, 2: 68-69.
} 
Santa Fe de Antioquia, desde donde se repartían a las labores de minas cercanas. Igualmente, por el sistema de bogas, la manteca llegaba a casi todos los puertos sobre el río Magdalena, en los cuales se carecía de otros aceites tanto para alumbrarse como para cocinar.

Al descubrir las posibilidades que ofrecían los productos extraídos del manatí, los españoles lo incluyeron como parte del tributo que debían pagar las encomiendas. El año para algunos de estos pueblos se alternaba de la siguiente manera: las épocas secas se las dedicaba a la pesca tradicional, y con atarrayas se atrapaban bagres y doncellas; en tiempo de lluvias, se cazaba manatíes, actividad que podía durar de uno a tres meses. Para esta última actividad, los indios partían con algunas mujeres y niños en barquetas hacia las mantequeras: en estos sitios (que podían estar a una distancia relativamente larga de su pueblo, entre 2 y 10 leguas), los indios tenían los bohíos preparados para vivir el tiempo que empleaban en este menester. Allí llevaban las pailas de cobre que dadas por sus encomenderos para derretir la manteca y allí preparaban los aparejos de pesca, entre los cuales destacaban los arpones de acero, que también habían recibido de sus amos; pailas y arpones eran los objetos que debían proporcionar los españoles a los indios para que pudieran realizar la cacería y extracción de aceite, y sin duda estos últimos se convirtieron en los mayores aportes a esta práctica, pues con ellos se pudo realizar la labor con mayor eficacia que con las armas que antes utilizaban los indios, pues la piel del manatí es gruesa y difícil de perforar. Una vez las mujeres se acomodaban en las mantequeras y todo estaba listo para cuando llegaran las presas, los hombres partían en las barquetas hacia los sitios en que se alimentaban los manatíes. Desde las barquetas lanzaban los arpones; una vez que los atrapaban, los mataban y llevaban a las mantequeras. Allí era destajado al animal y se ponía al fuego la cola, que es la parte que más grasa contiene. Para esta tarea es necesario contar con mucha leña; si estaba cerca, la recogían las mujeres, de lo contrario iban los hombres. Mientras unos se encargaban de llenar las botijas, otros terminaban de destazar los restos del animal y preparaban las reservas de carne secándola al aire y salándola, para consumirla en el sitio -según las descripciones de la época, como chicharrones, cecinetas y tocinetas- o llevarla a sus hogares una vez terminada la temporada de caza ${ }^{60}$. Las botijas podían ser llevadas al amo a medida que se iban llenando o una vez los indígenas estuvieran de regreso en el pueblo. Por cada una de ellas se podían recibir cuatro reales.

Con el paso del tiempo, el número de manatíes comenzó a reducirse considerablemente; el oidor Villabona y Zubiaurre encontró, en su visita de 1611, que algunas de las mantequeras habían sido abandonadas y que los pocos animales que cazaban podían prepararse en los propios pueblos, pues ya no valía la pena

60 "Descripción de la ciudad de Tamalameque", 294; AGN (Bogotá), Colonia, Visitas de Bolivar, t. 1, fol. 983r; t. 4, fols. 409r, 603r; t. 5, fol. 165; t. 7, fol. 764. 
desplazarse a ellas para sacar solo unas cuantas botijas ${ }^{61}$. Esto llevó a que los tributos cambiaran un poco, pues los indios se dedicaron con mayor intensidad al trabajo en las bogas, en muchos casos acompañados de los negros, que finalmente los desplazarían por completo.

Aunque la manteca extraída era usada principalmente para alimentar las lámparas, eso no debe llevar a pensar que su uso culinario fuera despreciable. Para algunos era similar a la manteca del cerdo e incluso Fernández de Oviedo la encontraba muy buena para freír huevos, con una gran ventaja frente a las otras, pues el paso del tiempo no la ponía rancia ${ }^{62}$. El uso masivo de este aceite de manatí en la zona del alto Magdalena puede hacer olvidar que se consumía su carne. En parte, porque no ocurría lo mismo con la tortuga que con el manatí: no podía ser transportado completo hacia los sitios de abastecimiento, y como lo más valioso era el aceite, el resto quedaba al servicio de los indios, que podían saciar su apetito con esta carne. Así, los otros segmentos de la sociedad parecían estar lejos de consumirla. Esto debe ser matizado, pues si bien es cierto que la carne del manatí no tuvo los alcances geográficos de la de tortuga, era un alimento que los grupos más cercanos a los indígenas, como los mayordomos y los encomenderos, apreciaban y consumían $^{63}$. Y al ser un bastimento de carne salada, los indios podían venderla a los pasajeros que transitaban por el río Magdalena. La reducción progresiva de este animal impidió que su carne pudiera crear un gusto que trascendiera las riberas del río Magdalena.

\section{Lagartos: fieros y mansos}

La primera experiencia que se tuvo con el caimán fue de espanto, al ver su figura, mandíbulas y colmillos, y sus ataques casi siempre mortíferos, de los cuales no escapaban vacas, perros, caballos ni humanos. Como a los indios no les gustaba mucho la carne de caimán, era raro que los conquistadores la encontraran entre los bastimentos que intercambiaban con ellos; aunque sí la de babillas. Por eso las primeras experiencias que tuvieron los españoles con la carne de este lagarto fue en momentos de extrema necesidad o casualidad. Fernández de Enciso afirmó que él fue el primer español en matar a un caimán. Lo hizo en el Darién a mediados de la segunda década del siglo XVI. A pesar de su autoproclama, él mismo aclaró que fue un criado suyo el que le dio la punzada mortal al animal, pues las lanzas de los demás rebotaban contra su cuero. Después procedieron a desollarlo, destazarlo y

\footnotetext{
${ }^{61}$ Ibídem, t. 4, fols. 317v, 393r -393v.

${ }^{62}$ Gonzalo Fernández de Oviedo, Historia General y Natural de las Indias Islas y Tierra Firme del Mar Océano (1853; reimpresión, Madrid: Real Academia de la Historia, 1944), 3: 137. Agradezco al historiador Fernando Torres por haberme pasado este dato, que yo había desatendido en su momento.

${ }^{63}$ AGN (Bogotá), Colonia, Visitas de Bolívar, t. 5, fols. 559v, 560r, 580r.
} 
prepararlo: señaló que su carne era "blanca y gentil, olía a almizque, era buena de comer" ${ }^{64}$. Casi 20 años después, Cieza de León hacía parte de la compañía del capitán Alonso de Cáceres que iba en la conquista de las provincias de Urute, al suroccidente de la provincia de Cartagena. Cuando pasaban por el río San Jorge, encontraron un caimán por fuera del agua, al cual atacaron, mataron $\mathrm{y}$ despedazaron para comer, pues estaban hambrientos; si bien calmaron su necesidad, fueron más exigentes que Fernández de Enciso, ya que, según Cieza, era "mala carne, y de un olor muy enhastioso" ${ }^{65}$. Este último criterio fue el que se impuso entre los españoles, pues nadie más volvió a reivindicar las calidades de esta carne, a pesar de que muchos otros la consumieron en campañas de conquista. En parte se puede entender que las dificultades de su cacería desanimaran cualquier intento para crear un consumo habitual, y como los indios no acostumbraban comerlo, no era fácil encontrar un sustento que permitiera crear un sentido de gusto $^{66}$.

Que los indios no consumieran su carne no significa que no lo cazaran. Igual que con el manatí, en las épocas secas, algunos pueblos se iban a las playas de los ríos para matar estos animales, de los cuales extraían su grasa ${ }^{67}$. Los españoles se percataron de esto e hicieron que los indios les tributaran en botijas de esta grasa, las cuales se utilizaban exclusivamente para alumbrar, y podían valer hasta tres pesos en las tiendas ${ }^{68}$. Es muy probable que se aprovechara alguna parte de los caimanes para alimentarse en la temporada de caza, pero este hecho no aparece registrado en los documentos. En cambio, los indios buscaban con afan los huevos de caimán en las playas, para comerlos gustosamente. En la conquista, los españoles aprendieron a buscarlos también y a consumirlos en momentos en que las necesidades los apremiaban. En Santa María la Antigua, en el golfo del Darién, a mediados de 1514, "dábanle [a quien vendía una nidada de huevos] cinco o seis castellanos, y más, según los que traían, a razón de un real de plata por cada huevo" 69 . Hay que recordar que Santa María la Antigua fue una de las primeras fundaciones de la tierra firme, y que allí se registró una gran mortandad de hambre: cerca de 700 españoles murieron en menos de un mes ${ }^{70}$. Esto explica el alto precio que alcanzaron estos huevos. También los de las tortugas y las iguanas fueron

\footnotetext{
${ }^{64}$ Martín Fernández de Enciso, Summa de Geografia (Bogotá: Banco Popular, 1974), 274.

${ }^{65}$ Cieza de León, Crónica del Perú, parte 1, cap. 2: 9.

${ }^{66}$ Incluso hoy en día, algunas comunidades amazónicas sólo consumen la carne del caimán cuando no encuentran su sustento básico. Luis Alberto Miño Rueda, "Los últimos cazadores de caimanes”. El Tiempo (Bogotá), 16 de mayo de 2004, sección 3, p. 1.

${ }^{67}$ AGN (Bogotá), Colonia, Miscelánea, t. 12, fols. 335v y ss; AGN (Bogotá), Colonia, Visitas de Bolivar, t. 4, fol. 425r.

${ }^{68}$ Ibídem, t. 5, fol. 179r.

${ }^{69}$ Fernández de Oviedo, Sumario, cap. 57: 146.

${ }^{70}$ Pascual de Andagoya, "Relación que da el adelantado de Andaboya de las tierras y probincias que abaxo se ara mención (1514)”, en Tovar, Relaciones y visitas, 1: 106.
} 
desenterrados y llegaron a la mesa de los españoles, que no pusieron reparos por su sabor, sino por su consistencia, pues no correspondía por completo a la de los huevos de las gallinas, sino que era suave y sin cáscara firme ${ }^{71}$.

Cuando ya hubo suficientes gallinas y los indios debían entregar los huevos de estas aves como parte de su tributo, los de las tortugas, las iguanas y los caimanes empezaron a ser vistos con desconfianza y fueron apartados de la dieta de los españoles, pues ya no eran necesarios. Sin embargo, indios y negros no dejaron de consumirlos, pues representaban un suplemento proteínico importante para sus $\operatorname{dietas}^{72}$; de esa manera se fue creando una identidad en torno a los huevos, que dividía los grupos sociales con cierta claridad; aún así las fronteras siempre son permeables, y cada español que navegaba por el río Magdalena entre los siglos XVI y XVII debía consumir los huevos que los indios desenterraban, en caso de que se los quisieran vender ${ }^{73}$.

Ahora bien, la carne de iguana fue apreciada desde el principio por su sabor y consistencia. Cómo ya se mencionó anteriormente, fue comparada con algunos animales de carne blanca, como el conejo y algunas aves. Los españoles aprendieron las maneras de prepararla que utilizaban los indios y la saborearon ${ }^{74}$, pero también pusieron a la iguana dentro de su propio umbral de experiencias y la comenzaron a preparar según patrones establecidos para otros productos que les resultaban comparables, pues, como aconsejaba Fernández de Oviedo:

[...] hánla de coçer e guisar de la misma manera que una gallina; y con sus espeçias e un pedaço de toçino y una berça no hay mas que pedir en este caso para los que conosçen este manjar ${ }^{75}$.

Esto ocurría porque, como ha explicado Montanari:

La cocina y el régimen alimentario no son un cúmulo casual de elementos, sino un conjunto global y coherente. De ahí la dificultad para aceptar y

\footnotetext{
${ }^{71}$ Fernández de Enciso, Summa de Geografía, 274; a Exquemelin los huevos de caimán se le asemejaban a los de ganso. Exquemelin, Historia de piratas, 20 de marzo, 141.

${ }^{72}$ Portocarrero, Descripción del virreinato, 119.

73 "Descripción de la villa de Tenerife de las cosas de la tierra que mandó azer el muy ilustre señor don Lope de Orozco, g[obernad]or de la ciudad de Santa Marta y sus provincias por su Majestad (19 de mayo de 1580)", en Tovar, Relaciones y visitas, 2: 345.

74 "Abriéndolas desde el gaznate hasta la ingle, lavadas y mondadas con esmero, y colocadas después en círculo, a modo de serpiente que durmiese enroscada dentro de una olla con capacidad sólo para su cuerpo, la rocían con un poco de agua con pimienta de la isla, comprímenla luego y la ponen sobre un fuego suave con cierta leña olorosa que no produce ningún humo". Anglería, Décadas del Nuevo Mundo, 1: 157.

${ }^{75}$ Fernández de Oviedo, Historia general y natural, t. 1: 396.
} 
comprender lo que es distinto, de ahí la necesidad de "filtrarlo" a través de nuestro sistema de valores, a menudo desnaturalizándolo. En cualquier caso adaptándolos, reduciéndolo a nuestras medidas ${ }^{76}$.

A pesar de sus cualidades, del gusto que encontraron en ella y de la forma como la insertaron en sus esquemas gustativos, en los tributos aparece muy poco. Era casi una actividad marginal de las encomiendas que se encontraban en las zonas en las cuales habitaba la iguana. De tanto en tanto, aparecen unas pocas iguanas que eran entregadas al encomendero para el consumo de su propia casa ${ }^{77}$. La respuesta a este silencio puede residir en que, al no ser un alimento para conservar, no tenía sentido cazar muchas ni se podían emplear como bastimentos para los viajes, así que se buscaba tener un abastecimiento ajustado a las necesidades diarias. La iguana se convirtió en un producto casero, en un gusto que se desarrollaba en los hogares o incluso en las pulperías y tabernas, pero que no hacía parte del gran mercado de la carne de tortuga o el aceite de manatí. También hay que tener en cuenta un factor similar al que se vio en el caso de los huevos: al aumentar el número de gallinas, no hubo necesidad de contar con substitutos; así la iguana ocupó un lugar menor en la mesa de los españoles, pero no en la de indios y negros, que siguieron monteándola con placer.

\section{Del chiquero a la tierra y de la tierra al agua}

He tratado de mostrar de qué manera se desarrolló el consumo de ciertos animales en algunas zonas cálidas del Nuevo Reino de Granada. Es verdad que faltan regiones de tierra caliente como la Gobernación de Santa Marta, la provincia de los Pijaos y la provincia de San Juan de los Llanos al oriente del Nuevo Reino. Sin embargo, las que se han estudiado tenían, aparte del clima, dos características más que las unían: alta frecuencia de tránsito comercial y necesidad de proveer bastimentos para que este funcionara. Por su parte, las que han quedado por fuera tenían muy poco movimiento de mercancías y personas: en el puerto de Santa Marta atracaban escasas naves desde el descubrimiento del canal de las Bahamas, a mediados del siglo XVI, y con la fundación de Cartagena, su situación se volvió casi dependiente de este otro puerto; en cuanto a la provincia de los Pijaos, apenas pudo ser pacificada en la segunda década del siglo XVII. La provincia de San Juan de los Llanos tuvo un índice demográfico de españoles muy bajo, y las villas que allí se fundaron eran la avanzada de una frontera que trataba de expandirse, pero que carecía de un número elevado de contactos. Indudablemente, en estas regiones se formaron patrones alimentarios de consumo de carnes que será necesario estudiar posteriormente. Asimismo para los habitantes de las zonas frías, donde se

\footnotetext{
${ }^{76}$ Montanari, Del hambre a la abundancia, 100-101.

${ }^{77}$ AGN (Bogotá), Colonia, Visitas de Bolivar, t. 1, fol. 344r.
} 
pudo desarrollar un modelo más cercano al ibérico, aunque con unas proporciones de consumo mucho más altas.

Las zonas que se han estudiado acá son principalmente la Gobernación de Cartagena y algunas márgenes del río Magdalena que bañaban parte de las gobernaciones de Antioquia, Cartagena y Santa Marta. En los casos del cerdo y la tortuga, la investigación se ha centrado en la parte costera de la primera gobernación y se ha incluido a las Antillas de manera tangencial, aunque no pertenecieran al Nuevo Reino de Granada, porque allí se configuró una región que compartía un tipo de alimentación, de valores y de creencias acerca de dos tipos de carne. Esta región no estaba circunscrita a los límites políticos de una sola gobernación o audiencia, pues, además de pertenecer a la Gobernación de Cartagena y las Antillas Españolas -que estaban bajo la Audiencia de Santo Domingo-, también la conformaban las posesiones francesas y las islas ocupadas por bucaneros holandeses y filibusteros de todas las naciones. En el caso del manatí, el hilo de unión es el río Magdalena, y nuevamente es claro que la regionalización no corresponde a un orden político, pues incluía parte de la Gobernación de Cartagena, parte de la de Santa Marta y parte de la de Antioquia.

Esta regionalización se elaboró a partir del comercio y la navegación trasatlántica e interna del reino y se estableció en torno a tres ejes: demanda de alimentos, producción establecida con mano de obra indígena y creación de un gusto o valoración de un producto. Si bien las dos primeras variables son muy importantes, quiero resaltar la última, porque sin ella es imposible comprender las dietas que se crearon en los siglos XVI y XVII. Además, si no contamos con esta última variable, el análisis quedaría circunscrito a un problema de oferta y demanda que no explica cómo se afectaba a la dieta, el gusto y las valoraciones que se hacían de los productos ni la creación de identidades alimentarias.

El cerdo, la tortuga, el manatí, la iguana y el caimán estuvieron presentes de diferentes formas en la dieta de las sociedades que se construyeron en las zonas cálidas que se han estudiado. Pero más importante aún, su manera de consumirlas difirió de la de otras zonas. Y si bien el gusto de estas sociedades estaba ligado a una matriz ibérica y tenía fuertes lazos con la indígena, la manera como hicieron de estos animales sus alimentos fue novedosa en sí misma y configuró un patrón específico que se puede identificar como indiano, irreductible a las dos experiencias previas. A través de españoles de todos los reinos, africanos de muchos pueblos, indios de diversas etnias, zambos de variados colores, mulatos de tonalidades múltiples, mestizos y criollos circuló la información sobre los tipos de cocciones, las cualidades de las carnes y los secretos de las cocinas, y se creó un panorama único. Sin embargo, que la información circulara no significa que la compartieran y que todos pensaran igual; cada grupo y cada individuo hacía sus propias interpretaciones, valoraciones y configuraba su gusto de acuerdo con sus posibilidades económicas y culturales. 
Los cambios en las dietas no solo formaron un gusto nuevo, sino que hasta cierto punto incidieron en la visión sobre el mundo, la salud y lo deseable. Si bien no se puede calificar como una revolución cárnica, lo cierto es que la experiencia indiana, en especial la de las zonas cálidas que se han estudiado, fue tan singular que marcó una ruptura significativa en la tradición hispánica, para consolidarse como una alternativa más entre las muchas que había en ese mundo en construcción, múltiple, diverso e híbrido.

\section{Bibliografía}

\section{Fuentes primarias}

Archivo General de la Nación, Bogotá, Colombia.

Archivo General de la Nación, México.

Archivo Histórico de Antioquia, Medellín.

Colección de Documentos Inéditos de las Posesiones Españolas en América y Oceanía (CDIAO), Madrid.

\section{Fuentes secundarias}

Acosta, José de. Historia natural y moral de las Indias. México: Fondo de Cultura Económica, 1940.

Alberro, Solange. Del gachupín al criollo. O de cómo los españoles de México dejaron de serlo. México: El Colegio de México, 2002.

Andagoya, Pascual de. "Relación que da el adelantado de Andaboya de las tierras y probincias que abaxo se ara mención (1514)". En Relaciones y visitas a los Andes. Siglo XVI, ed. Hermes Tovar. T. 1:103-186. Bogotá: Colcultura, 1993.

Andrews, Jean. "Diffusion of Mesoamerican Food Complex to Southeastern Europe". The Geographical Review (Nueva York), 83 (abril 1993): 194204.

Anglería, Pedro Mártir de. Décadas del Nuevo Mundo. 2 t. México: Porrúa, 1964.

"Autos en razón de prohibir a los caziques de Fontibón, Ubaque y otros no hagan las fiestas, borracheras y sacrificios de su gentilidad [1563-1569]". En 
Relaciones y visitas a los Andes. Siglo XVI, ed. Hermes Tovar. t. 3, Región Centro Oriental, 239-265. Bogotá: Colcultura, 1995.

Barreto Ribas, Maria Aparecida de Araujo. $O$ pão do outro: alimentação e alteridade no Brasil colonial (1500-1627). Disertación de maestría en historia del programa interinstitucional UFF/Unioeste, Niterói, 2002.

Bernand, Carmen. Negros esclavos y libres en las ciudades hispanoamericanas. Madrid: Fundación Histórica Tavera; Fundación Hernando de Larramendi, 2001.

Bernand, Carmen y Serge Gruzinski. Historia del Nuevo Mundo. T. 1. México: Fondo de Cultura Económica, 1996.

Black, Maggie. The Medieval Cookbook. Londres: British Museum Press, 1996.

Caldas, Francisco José de. "Estado de la geografía del virreinato de Santafé de Bogotá, con relación a la economía y al comercio". En Obras completas de Francisco José de Caldas, 183-211. Bogotá: Universidad Nacional de Colombia, 1966.

Capatti, Alberto y Massimo Montanari. Italian Cuisine. A cultural History. New York: Columbia University Press, 2003.

Carletti, Francesco. Razonamientos de mi viaje alrededor del mundo (1594-1606), estudio preliminar, traducción y notas de Francisca Perujo. México: Instituto de Investigaciones Bibliográficas, Universidad Nacional Autónoma de México, 1976.

Castellanos, Juan de. Elegías de Varones Ilustres de Indias, ed. Gerardo Rivas Moreno. Cali: Fundación FICA, 1997.

Cieza de León, Pedro de. La crónica del Perú. Obras completas. T. 1. [¿1553?]; Madrid: CSIC; Instituto Gonzalo Fernández de Oviedo, 1984.

Contreras, Jesús. "Los aspectos culturales en el consumo de carne". En Somos lo que comemos, coord. Mabel Gracia Arnaiz. Barcelona: Ariel, 2002.

, comp. Alimentación y cultura. Necesidades, gustos y costumbres. Barcelona: Universitat de Barcelona, 1995.

Corcuera de Mancera, Sonia. Entre gula y templanza. Un aspecto de la historia mexicana. México: Fondo de Cultura Económica, 1996. 
Córdoba Ochoa, Luis Miguel. "Los mil forajidos de Antioquia y los mohanes de Ebejico". Anuario Colombiano de Historia Social y de la Cultura (Bogotá), 29 (2002): 7-44.

- "Las relaciones de meritos y la difusión de la cultura política castellana en indias". Tesis doctoral, Universidad Pablo de Olavide, Sevilla, 2003.

Del Río Moreno, Justo y Lorenzo López y Sebastián. "Hombres y ganados en la tierra del oro: Comienzos de la ganadería en Indias". Revista Complutense de Historia de América (Madrid), 24 (1998): 11-45.

"La ganadería vacuna en la isla Española (1508-1587)". Revista Complutense de Historia de América (Madrid), 25 (1999):11-49.

"Descripción de la ciudad de Tamalameque en la Gobernación de Santa Marta, 5 de marzo de 1579". En Relaciones y visitas a los Andes. Siglo XVI, ed. Hermes Tovar. t. 2, Región Caribe, 279-308. Bogotá: Colcultura, 1993.

"Descripción de la villa de Tenerife de las cosas de la tierra que mandó azer el muy ilustre señor don Lope de Orozco, g[obernad]or de la ciudad de Santa Marta y sus provincias por su Majestad (19 de mayo de 1580)". En Relaciones y visitas a los Andes. Siglo XVI, ed. Hermes Tovar. t. 2, Región Caribe, 309-354. Bogotá: Colcultura, 1993.

Domingo, Xavier. "La cocina precolombina en España". En Conquista y comida. Consecuencias del encuentro de dos mundos, coord. Janet Long. México: Universidad Nacional Autónoma de México, 1996.

Douglas, Mary. Purity and Danger. An Analysis of Concepts of Pollution and Taboo. Harmondsworth: Penguin books, 1970.

"Las estructuras de lo culinario". En Alimentación y cultura. Necesidades, gustos y costumbres, comp. Jesús Contreras. México: Alfaomega, 2002.

Estrada, Julián. "La alimentación desde la época prehispánica hasta nuestros días". En Historia de Antioquia. Medellín: Suramericana de Seguros, 1991. 
"Evolución y cambios en los hábitos alimentarios en Medellín, durante el siglo XIX". En Historia de Medellín, coord. Jorge O. Melo. T. 2: 201212. Medellín: Suramericana de Seguros, 1996.

"Epítome de la conquista del Nuebo Reino de Gra(na)da [ca. 1544]". En Relaciones y visitas a los Andes. Siglo XVI, ed. Hermes Tovar. t. 3, Región Centro Oriental, 121-143. Bogotá: Colcultura, 1993.

Exquemeling, Alexandre Olivier. Historias de piratas. Diario de un cirujano de a bordo. Buenos Aires: Biblioteca Fundamental del Hombre Moderno, 1972.

Fernández de Enciso, Martín. Summa de Geografia. [¿1519?]; Bogotá: Banco Popular, 1974.

Fernández de Oviedo, Gonzalo. Historia General y Natural de las Indias Islas y Tierra Firme del Mar Océano. 3 t. Madrid: Real Academia de la Historia, 1853.

Sumario de la natural historia de las Indias, ed. Manuel Ballestero Gaibrois. [¿1525?]; Madrid: Dastin, 2002.

Fernández de Piedrahíta, Lucas. Noticia historial de las conquistas del Nuevo Reino de Granada. [¿Bogotá ?]: Ediciones de la Revista Ximenez de Quesada, 1973.

Flandrin, Jean-Louis. "Le goût et la nécessité : sur l'usage des graisses dans les cuisines d'Europe occidentale (XIV $-\mathrm{XVIII}^{\mathrm{e}}$ siècle)". Annales ESC (París), 38, núm. 2 (marzo-abril 1983): 369-401.

"L'alimentation paysanne en économie de subsistance". En Histoire de l'alimentation, dirs. Jean-Louis Flandrin y Massimo Montanari, 597-627. París: Fayard, 1996.

y Massimo Montanari, dirs. Histoire de l'alimentation. París: Fayard, 1996.

Thomas Gage. Nueva relación que contiene los viajes de Tomás Gage a la Nueva España, sus diversas aventuras y su vuelta por la provincia de Nicaragua hasta la Habana, con la descripción de la ciudad de México, prólogo de Artemio de Valle-Arizpe. México: Ediciones Xochitil, 1947. 
García Marsilla, Juan Vicente. La jerarquía de la mesa. Los sistemas alimentarios de la Valencia bajomedieval. Valencia: Diputació de Valencia; Historia Local/13, 1993.

Ginzburg, Carlo. Historia nocturna. Un desciframiento del aquelarre. Barcelona: Mario Muchnick, 1991.

Ojazos de madera. Nueve reflexiones sobre la distancia. Barcelona: Península, 2000.

Tentativas. Morelia: Universidad Michoacana, 2003.

Gracia Arnaiz, Mabel, coord. Somos lo que comemos. Estudios de alimentación y cultura en España. Barcelona: Ariel, 2002.

Gruzinski, Serge. La colonización de lo imaginario. Sociedades indígenas y occidentalización en el México español. México: Fondo de Cultura Económica, 1991.

Guerreau-Jalabert, Anita. "Aliments symboliques et symbolique de la table dan les romans arthuriens (XII $-\mathrm{XIII}^{\mathrm{e}}$ siècles)". Annales ESC (París), 47, núm. 3 (mayo-junio 1992): 561-594.

Guhl, Ernesto. Colombia: bosquejo de su geografia tropical. 2 t. Bogotá: Instituto Colombiano de Cultura, 1975.

Gutiérrez de Ovalle. "Relación de La Trinidad y La Palma por Gutiérrez de Ovalle su conquistador (ca. 1572)". En Relaciones y visitas a los Andes. Siglo XVI, ed. Hermes Tovar. t. 3, Región Centro Oriental, 323-368. Bogotá: Colcultura, 1995.

Hastorf, Christine A. y Sisle Johannessen. "Pre-hispanic Political Change and the Role of Maize in the Central Andes of Peru". American Anthropologist (Arlington), 95 (marzo 1993): 115-138.

Herrera Ángel, Marta, Ordenar para controlar. Ordenamiento espacial y control politico en las llanuras del Caribe y en los Andes centrales neogranadinos. Siglo XVIII. Bogotá: Academia Colombiana de la Historia; Instituto Colombiano de Antropología e Historia, 2002.

Huarte de San Juan, Juan. Examen de ingenios para las ciencias, ed. Esteban Torre. [¿1575?]; Madrid: Editora Nacional, 1976. 
Huetz de Lemps, Alain. "Boissons coloniales et essor du sucre". En Histoire de l'alimentation, dirs. Jean-Louis Flandrin y Massimo Montanari, 629-641. París: Fayard, 1996.

"Indios de Bosa. Investigación sobre los malos tratos que les daban con motivo de la extracción de oro en el corregimiento de Ontibon de la Real Corona. Contra el licenciado Miguel Días". En Relaciones y visitas a los Andes. Siglo XVI, ed. Hermes Tovar. t. 3, Región Centro Oriental, 145-162. Bogotá: Colcultura, 1995.

"Interrogatorio sobre el pleyto entre Gonzalo Suarez y Pero Vazquez por los yndios de Ycabuco [ca. 1550]". En Relaciones y visitas a los Andes. Siglo XVI, ed. Hermes Tovar. t. 3, Región Centro Oriental, 165-203. Bogotá: Colcultura, 1995.

Kislinger, Ewald, "Les chrétiens d'Orient : règles et réalités alimentaires dans le monde byzantin". En Histoire de l'alimentation, dirs. Jean-Louis Flandrin y Massimo Montanari, 319-344. París: Fayard, 1996.

Labat, Jean-Baptiste. Viaje a las islas de América. La Habana: Casa de las Américas, 1979.

"La ciudad de los Reyes Valle de Upar [1578]". En Relaciones y visitas a los Andes. Siglo XVI, ed. Hermes Tovar. t. 2, Región Caribe, 231-278. Bogotá: Colcultura, 1993.

Laet, Joannes de. Mundo nuevo o descripción de las Indias occidentales. Caracas: Universidad Simón Bolívar; Instituto de Altos Estudios de América Latina, 1988.

Las Casas, Bartolomé de. Historia de las Indias. México: Fondo de Cultura Económica, 1981.

López Medel, Tomás. Tratado de los tres elementos. Madrid: Alianza, 1992.

López de Velasco, Juan. Geografia y descripción universal de las Indias, ed. Marcos Jiménez de la Espada. Madrid: Atlas, 1971.

Martínez, Aída. Mesa y cocina en el siglo XIX. Bogotá: Planeta, 1990.

Medrano, Alonso. "Descripción del Nuevo Reino de Granada (1598)", trascripción y presentación Michael Francis. Anuario Colombiano de Historia Social y de la Cultura (Bogotá), 30 (2003): 341-360. 
Meléndez, fray Juan. Tesoros verdaderos de las Yndias. En la historia de la gran provincia de San Juan Bautista del Perú de el Orden de predicadores. t. 3. Roma: Imprenta de Nicolás Ángel Tinassio, 1682.

Méndez, Cristóbal. Libro del ejercicio corporal y de sus provechos por el cual cada uno podrá entender qué ejercicio le sea necesario para conservar su salud. México: Academia Nacional de Medicina, 1991.

Méndez Nieto, Juan. Discursos medicinales compuestos por el licenciado Juan Mendez Nieto, que tratan de las maravillosas curas y sucesos que dios nuestro señor a querido obrar por sus manos, en cinquenta años que a que cura, ansi en España, como en la ysla española, y rreino de tierra firme, [...] En Cartagena indiana, año de 1607 y de la hedad del autor 76. [...]. Salamanca: Universidad de Salamanca; Junta de Castilla y León, 1989.

Mintz, Sidney W. "El dulce intruso: el azúcar en el Nuevo Mundo". En Conquista y comida. Consecuencias del encuentro de dos mundos, coord. Janet Long. México: Universidad Nacional Autónoma de México, 1996

Miño Rueda, Luis Alberto. "Los últimos cazadores de caimanes". El Tiempo (Bogotá), 16 de mayo de 2004, sección 3, p. 1.

Montanari, Máximo. Del hambre a la abundancia. Historia y cultura de la alimentación en Europa. Barcelona: Crítica, 1993.

"Mortuoria de Ana Ancerma, yndia del pueblo de San Lorenzo de Aburrá, 1627". Trascripción y presentación Gregorio Saldarriaga. Historia y Sociedad (Medellín), 7 (2000): 227-237.

Motis Dolader y Miguel Ángel. "L'alimentation juive médiévale". En Histoire de l'alimentation, dirs. Jean-Louis Flandrin y Massimo Montanari, 367-387. París: Fayard, 1996.

Musset, Alain. El agua en el valle de México, siglos XVI-XVIII. México: Pórtico de la Ciudad de México; Centro de Estudios Mexicanos y Centroamericanos, 1992.

Ocaña, Diego de. A través de la América del Sur, ed. Arturo Álvarez. Madrid: Historia 16, 1987. 
Ovando y Godoy, Juan. Gobernación espiritual de Indias. Código Ovandino, libro primero, presentación y trascripción Ángel Martín González. [¿1570?]; Guatemala: Instituto Teológico Salesiano, 1978.

Pérez de Arteaga, Melchor. "Relación del Nuevo Reino (1568)". En No hay caciques ni señores, Hermes Tovar. Barcelona: Sendai, 1988.

[¿Portocarrero, León?]. Descripción del virreinato del Perú. Rosario: Universidad Nacional del Litoral, 1958.

Reichel-Dolmatoff, Gerardo. El chamán y el jaguar. Estudio de las drogas narcóticas entre los indios de Colombia. México: Siglo XXI, 1978.

Reitz, Elizabeth. "Dieta y alimentación hispano-americana en el Caribe y la Florida en el siglo XVI". Revista de Indias (Madrid), 51, núm. 191 (1991):11-24.

"Relación de la conquista de los Carares [9 de mayo de 1601]". En Relaciones y visitas a los Andes. Siglo XVI, ed. Hermes Tovar. T. 3, Región Centro Oriental, 427-482. Bogotá: Colcultura, 1995.

"Relación de las cosas notables que hay en el distrito de esta audiencia de el Nuevo Reyno de Granada [ca. 1608]". En Relaciones y visitas a los Andes. Siglo $X V I$, ed. Hermes Tovar. t. 3, Región Centro Oriental, 483-501. Bogotá: Colcultura, 1995.

Restrepo, Cecilia y Helena Saavedra. De la sala al comedor. Anécdotas y recetas bogotanas. Bogotá: Binah, 2004.

Robledo, Jorge. "Relación de Anzerma". En Relaciones y visitas a los Andes. Siglo XVI, ed. Hermes Tovar. T. 1:335-364. Bogotá: Colcultura, 1993.

Rodríguez Freyle, Juan. Conquista y descubrimiento del Nuevo Reino de Granada, ed. Jaime Delgado. Madrid: Dastin, 2000.

Rodríguez de León Pinelo, Antonio. Tratado de confirmaciones reales. Copia facsimilar. [¿1630?]; Caracas: Academia Nacional de la Historia, 1972.

Romero, Mario Germán. Fray Juan de los Barrios y la evangelización del Nuevo Reino de Granada. Bogotá: ABC, 1960.

Rosenberg, Bernard. "La cuisine arabe et son apport à la cuisine européene". En Histoire de l'alimentation, dirs. Jean-Louis Flandrin y Massimo Montanari, 345-365. París: Fayard, 1996. 
Saldarriaga, Gregorio. "La inserción del maíz en el gusto de la sociedad colonial del Nuevo Reino de Granada". Historia y Sociedad (Medellín), 6 (1999): 84-106.

"Redes y estrategias femeninas de inserción social en tierra de frontera: tres mujeres desarraigadas en Antioquia, siglo XVII". En Las mujeres en la construcción de las sociedades iberoamericanas, eds. Pilar Gonzalbo y Berta Ares, 141-161. México y Sevilla: El Colegio de México; Escuela de Estudios Hispano-americanos, 2004.

Sardela, Juan Bautista. "Relación de lo que subcedio al magnifico señor capitan Jorge Robledo (ca. 1540)". En Relaciones y visitas a los Andes. Siglo XVI, ed. Hermes Tovar. T. 1:263-334. Bogotá: Colcultura, 1993.

Sevilla, San Isidoro de. Etimologías, trad. Luis Cortés y Góngora. Madrid: Biblioteca de Autores Cristianos, 1951.

Simón, fray Pedro. Noticias historiales de las conquistas de Tierra Firme en las Indias Occidentales. 7 t. [¿1628?]; Bogotá: Banco Popular, 1982-1982.

Splendiani, Ana María y otros. Cincuenta años de inquisición en el tribunal de Cartagena de Indias 1610-1660. 4 t. Bogotá: Instituto Colombiano de Cultura Hispánica; Ceja, 1997.

Steinmetz, Rudy. "Conceptions du corps a travers l'acte alimentaire aux XVII et XVIII ${ }^{\mathrm{e}}$ siècles". Revue d'histoire moderne et contemporaine (París) 35 (enero-marzo 1998): 3-35.

Super, John C. Food, Conquest, and Colonization in Sixteenth-Century Spanish America. Albuquerque: University of New Mexico Press, 1988.

Tovar, Hermes. No hay caciques ni señores: relaciones y visitas a naturales de América, siglo XVI. Barcelona: Sendai, 1987.

Relaciones y visitas a los Andes. 4 t. Bogotá: Colcultura, 1993-1995.

Vainfas, Ronaldo. "Colonialismo e idolatrías: Cultura y resistencia indígena en el mundo ibérico". En Pueblos y culturas indígenas. Quito: Adhilac, 1992.

"Idolatrias e milenarismos: a resistência indígena nas Americas". Estudos Históricos (Sao Paolo), 5, núm. 9 (1992): 29-43. 
Vargas Lesmes, Julián. La sociedad de Santa Fe Colonial. Bogotá: Cinep, 1990.

Vargas Machuca, Bernardo. Milicia y descripción de las Indias. Bogotá: CESO; Biblioteca Banco Popular, 2003.

Warman, Arturo. Historia de un bastardo: maíz y capitalismo. México: Fondo de Cultura Económica, 1988.

Fecha de recepción: 27 de enero de 2006.

Fecha de aceptación: 14 de junio de 2006. 